Mykola Sysyn - Dimitri Gruen - Ulf Gerber - Olga Nabochenko - Vitalii Kovalchuk*

\title{
TURNOUT MONITORING WITH VEHICLE BASED INERTIAL MEASUREMENTS OF OPERATIONAL TRAINS: A MACHINE LEARNING APPROACH
}

\begin{abstract}
A machine learning approach for the recent detection of crossing faults is presented in the paper. The basis for the research are the data of the axle box inertial measurements on operational trains with the system ESAH-F. Within the machine learning approach the signal processing methods, as well as data reduction classification methods, are used. The wavelet analysis is applied to detect the spectral features at measured signals. The simple filter approach and sequential feature selection is used to find the most significant features and train the classification model. The validation and error estimates are presented and its relation to the number of selected features is analysed, as well.

Keywords: turnouts, inertial measurement systems, predictive maintenance, signal processing, data mining, machine learning, data reduction, feature selection
\end{abstract}

\section{Introduction}

Common crossing of turnout is one of the weakest elements of the railway superstructure. Despite many attempts in the last years to prolong its lifecycle [1-3], it is still 5-10 times lower than the lifetime of the ordinary rail track [4]. Moreover, the maintenance costs for turnouts are comparatively high due to demand for frequent inspections with relatively low automatisation. The process of common crossing deterioration is to a great extent difficult to predict and thus to plan the maintenance works [3]. That can often cause big expenses because of unplanned traffic interruptions and train delays.

Its application on operational trains could provide almost continuous monitoring of the track state.

The inertial measurement systems ESAH-M and ESAH-F are developed with the DB AG (German railway company) for the estimation of common crossings. The systems provide acceleration measurements complemented by positioning sensors on track [5-6] with Electronic Analysis System of Crossing Portable (German ESAH-M, Figure 1, left). The vehicle axle box measurements [6-8] are provided with Electronic Analysis System of Crossing - Train (German ESAH-F, Figure 1, right).

The main problem of inertial measurements on railway track is a rather big uncertainty together with unknown criteria for the corresponding maintenance works [9]. A lot of recent researches are devoted to this problematic. A quantitative relationship between the characteristics of the axle box accelerations and the track defects for their early detection is proposed in [10-11]. The acquisition of axle box accelerations with their time-frequency analysis is shown in [12-13] for track monitoring purposes. Vibration-based condition monitoring was suggested in [14], based on in-situ measurements of the crossing vibrations of a railway turnout.
The data mining methods are widely used in transportation research. The data-driven rail-infrastructure monitoring that is based on data fusion, feature extraction, selection and other data mining methods are depicted in [15]. In [16] authors describe the general methodology of big data analytics for track maintenance planning. An example of track quality analysis for the track maintenance with application of the machine learning methods is presented in [17]. The support vector classification and regression methods are used for optimization of freight traffic planning, [18]. The application of big data analysis of surface defect measurements together with axle box acceleration is used to facilitate grinding planning of rail segments, [19]. The big-data fusion and incremental learning is applied to solve the problem of position synchronization for the track geometry inspection, [20]. In the present paper, the sequential feature selection is used to find out the meaningful spectral features that correspond to the state of turnout immediately before its fault. The statistical model is developed to identify the state with the axle box acceleration measurements.

\section{Data pre-processing and feature extraction}

The inertial measurements of ESAH-F system are subjected to a big number of unknown and unconsidered factors, such as the wheel profile irregularities and wear, lateral wheel position, etc.

This leads to a big deviation of measurement results that makes it very difficult to estimate the changes of a common crossing state. The usually used analysis of maximal axle box accelerations shows almost no changes of the value until the first crack of the rolling surface in common crossing occurs (Figure 2). This means that the conventional analysis suits well for condition monitoring of common crossings by detecting defects. Though the

\footnotetext{
* ${ }^{1}$ Mykola Sysyn, ${ }^{1}$ Dimitri Gruen, ${ }^{1}$ Ulf Gerber, ${ }^{2}$ Olga Nabochenko, ${ }^{2}$ Vitalii Kovalchuk

${ }^{1}$ Institute of Railway Systems and Public Transport, Technical University of Dresden, Germany

${ }^{2}$ Department of the rolling stock and track, Lviv branch of Dnipropetrovsk National University of Railway Transport, Lviv, Ukraine

E-mail: mykola.sysyn@tu-dresden.de
} 

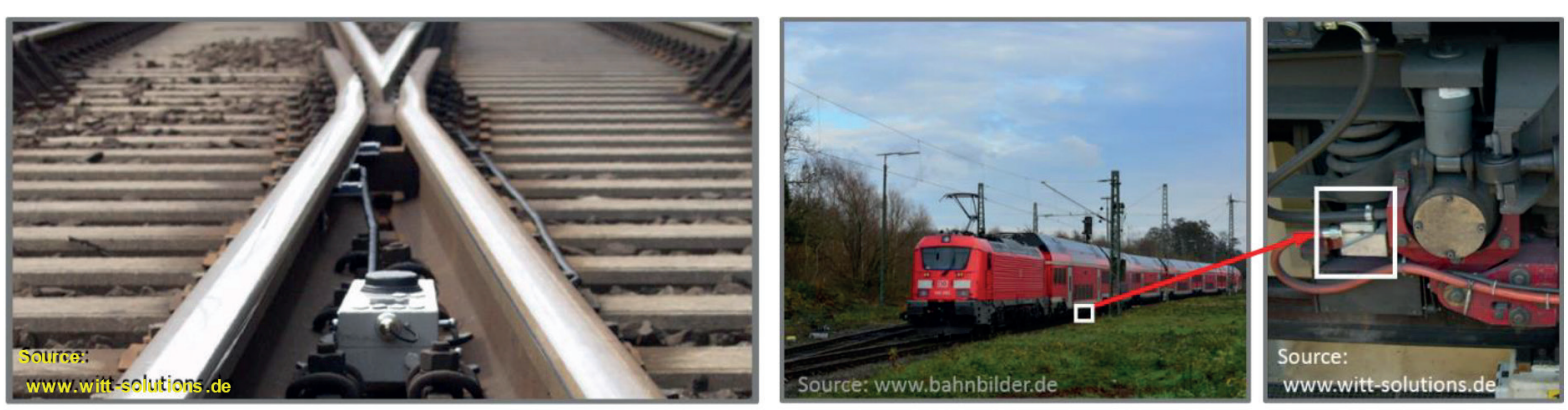

Figure 1 The inertial measurement systems (left - ESAH-M, right - ESAH-F)

1. after ca. 7 megatons - no defects
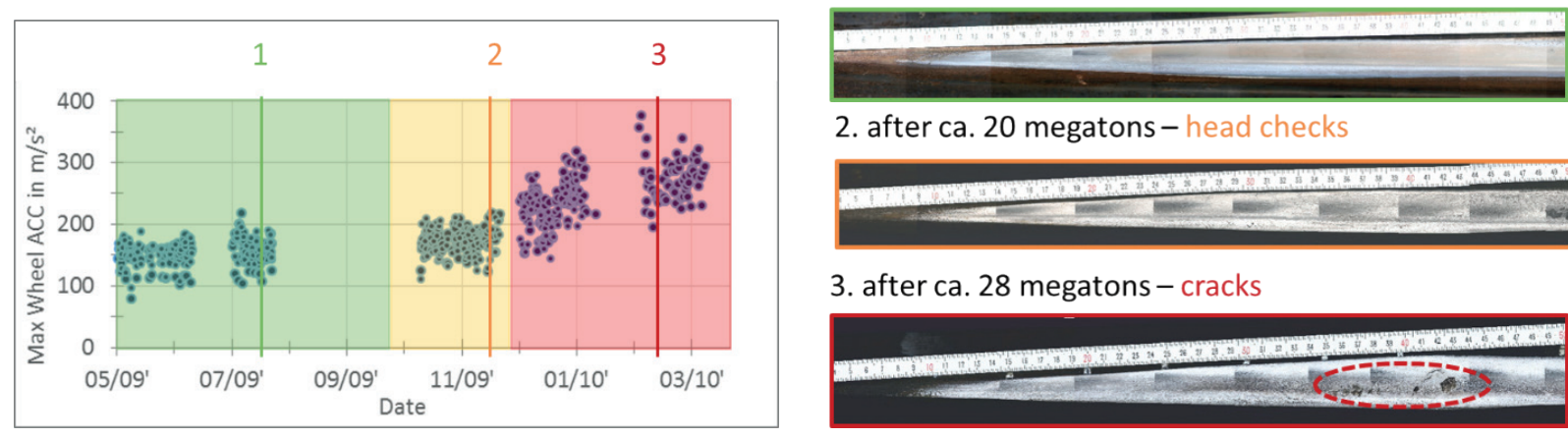

2. after ca. 20 megatons - head checks

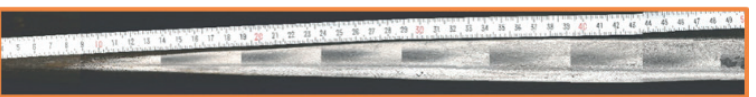

3. after ca. 28 megatons - cracks

Figure 2 Wheel ACC Amplitudes during the lifecycle (left) and surface images of a common crossing (right). Photo material: $D B$ Systemtechnik GmbH

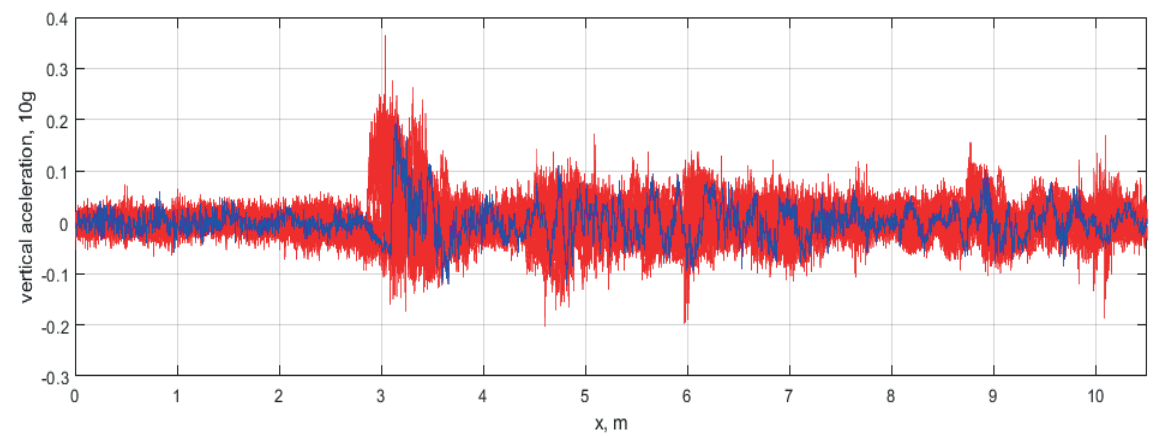

Figure 3 Example of the wheel ACC measurement (blue) and group of the wheel ACC measurements (red)

faults are unexpected and often unpredictable, that leads to big expenses due to unplanned maintenance works and traffic delays.

The statistical analysis is based on the acceleration measurements of the ESAH-F system of the DB Systemtechnik. The measurements were carried out at operational passenger double-decker trains on two axle boxes of one bogie.

The turnouts number as well as motion direction were detected by the GPS. The sampling rate used is $50 \mathrm{kHz}$. The analysed turnout of type $1 / 12$ was measured along all its lifecycle ca. 32 megatons. The operating load at turnouts was 27 megatons per year with mixed traffic. The general number train passages is 229 , with 2 axle box 3D acceleration measurements. The typical measurement of 1 vertical acceleration together with the cloud of other measurements is shown at Figure 3.

The measurements are divided for the statistical analysis in two groups:

- the beginning of lifecycle: 52 measurements with 104 acceleration records;
- 1.5 months before the first visible squats appearing: 73 measurements with 107 successful records.

The wavelet transform was used to extract the feature set from the random enough time series of acceleration measurements. The Signal Processing, Statistics and Machine Learning Toolboxes are used for data processing and analysis [21].

All the data are synchronised with the maximal acceleration point. Time axis is changed to wheel position coordinate to reduce the influence of different train velocities. The example of signal spectral density distribution along the $11 \mathrm{~m}$ track and frequency range $0-25 \mathrm{kHz}$ is shown in Figure 4. The low accelerations due to ballast settlements and wing-frog rail rolling surface begin $3 \mathrm{~m}$ before the impact point. The maximal acceleration appear at the impact point with frequency range $90-750 \mathrm{~Hz}$. The highest accelerations reach up to $20 \mathrm{kHz}$. The spectral components of signal in Figure 4 can be visually divided into 3 main groups: lower than $800 \mathrm{~Hz}, 800-4000 \mathrm{~Hz}$ and $4000-20000 \mathrm{~Hz}$. 


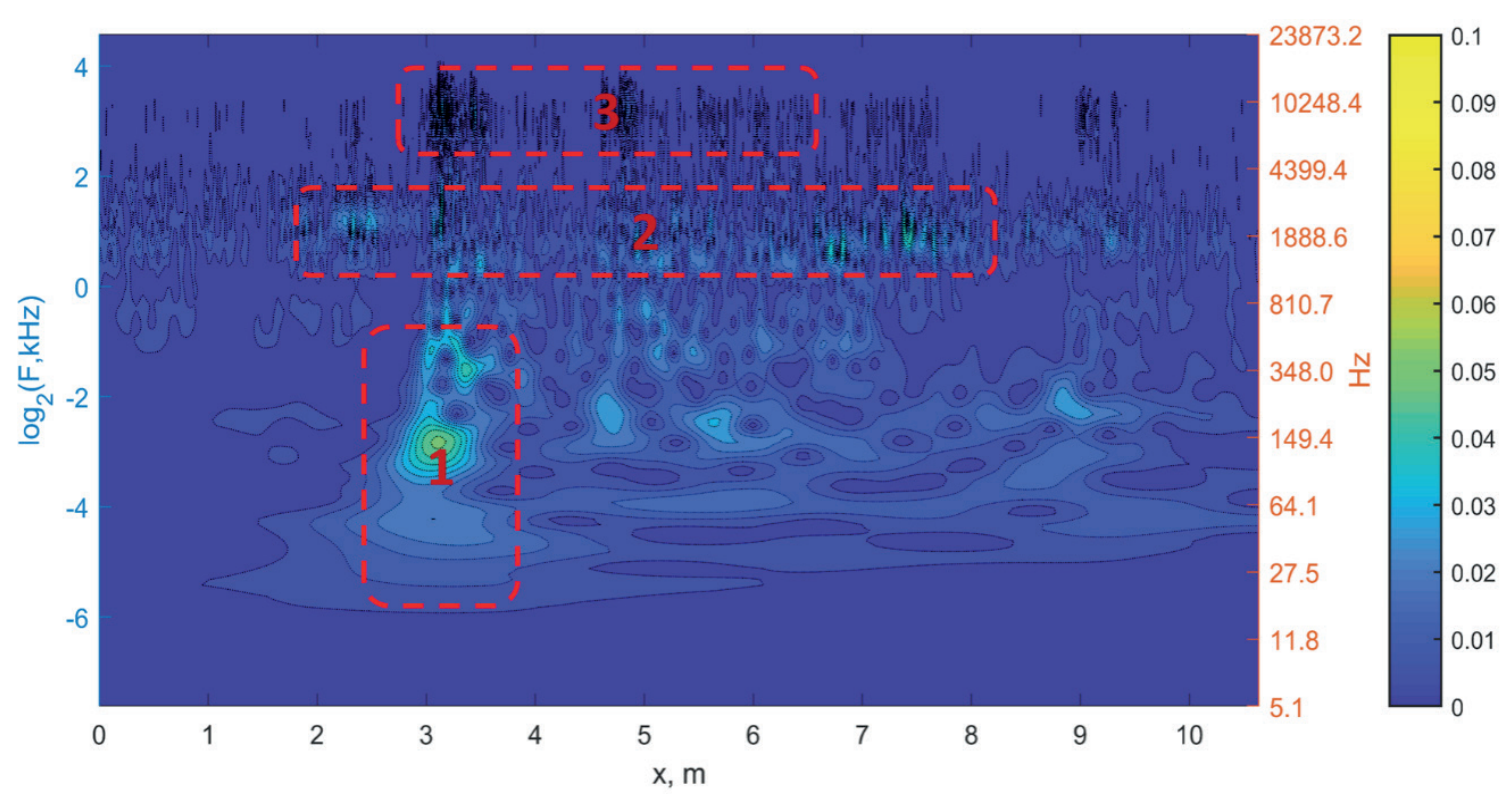

Figure 4 Example of spectral density distribution along $11 \mathrm{~m}$ track (common crossing at position 2-4 m)
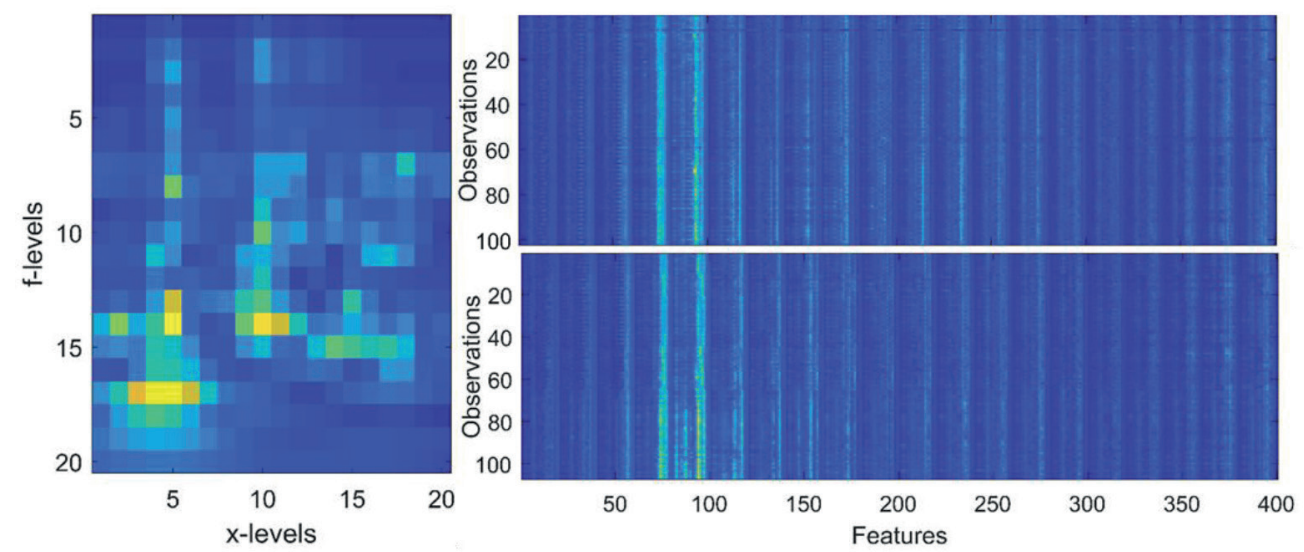

Figure 5 Example of features reduction $20 \times 20$ (left) and their collection for two periods of lifetime (right: $1^{\text {st }}$ group - above, $2^{\text {nd }}$ group - below, see Figure 2)

To receive the limited number of features for each observation, the wavelet coefficients are segmented in raster $20 \times 20$ that correspond to logarithmic frequency range $10 \mathrm{~Hz}-20 \mathrm{kHz}$ and longitudinal coordinate $1.5-8.5 \mathrm{~m}$. Overall number of features are limited to 400 . The segmented and collected features for two groups are shown in Figure 5.

\section{Feature selection}

The goal feature selection is to reduce the dimension 400 of the data by finding a small set of important features, which can give good classification performance. Feature selection algorithms are divided into 3 categories [22]: filter methods, wrapper methods and embedded methods. The simplest filter method of sequential feature selection is used for the present research. It does not consider the relationships between variables but is effective in computation time and robust to overfitting.

To estimate the performance of a classification model another data set should be chosen that was not used to build the model.
All 211 observations are divided into a training set of size 155 and a test set of size 56 . The model is tested in two ways: holdout validation and cross-validation. Within the holdout validation the features are selected using the training data and the performance is judge based on the test data.

To find out how well the two groups (Figure 5) are separated by each feature, the pairwise t-test statistic is applied [21]. Figure 6 shows the difference between the groups and the critical value of feature to reject the null hypothesis.

According to Figure 6, there are a lot of features with statistically significant differences between the groups. The diagram of empirical cumulative probability of null hypothesis (Figure 7) shows that there are about $50 \%$ features with strong discrimination power.

Even though there are big statistical differences between the groups, it is not enough to estimate the classification uncertainty and decide how many features are necessary. A statistical model should be developed to classify new observations to the corresponding group. The model is developed within the quadratic discriminant analysis (QDA) [23]. The classification 


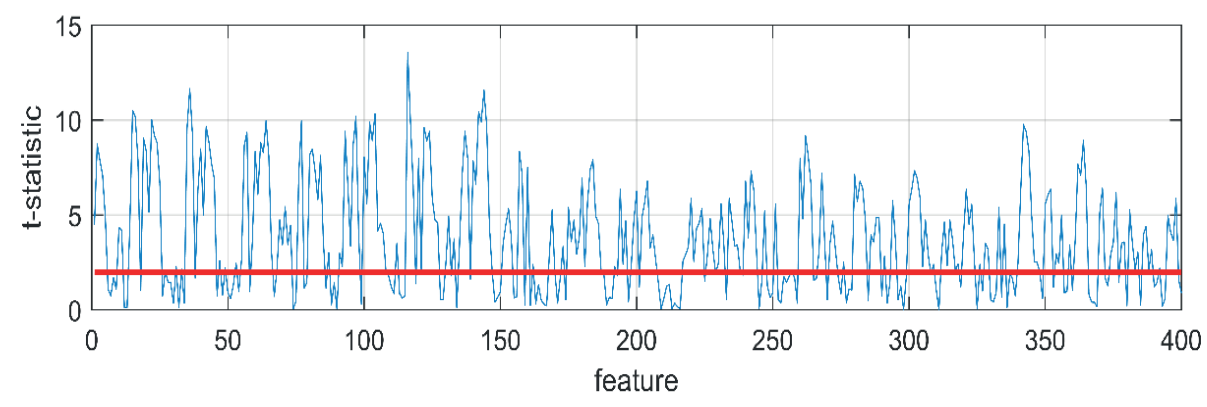

Figure 6 T-Statistic for features values (blue) and threshold for the null hypothesis (red)

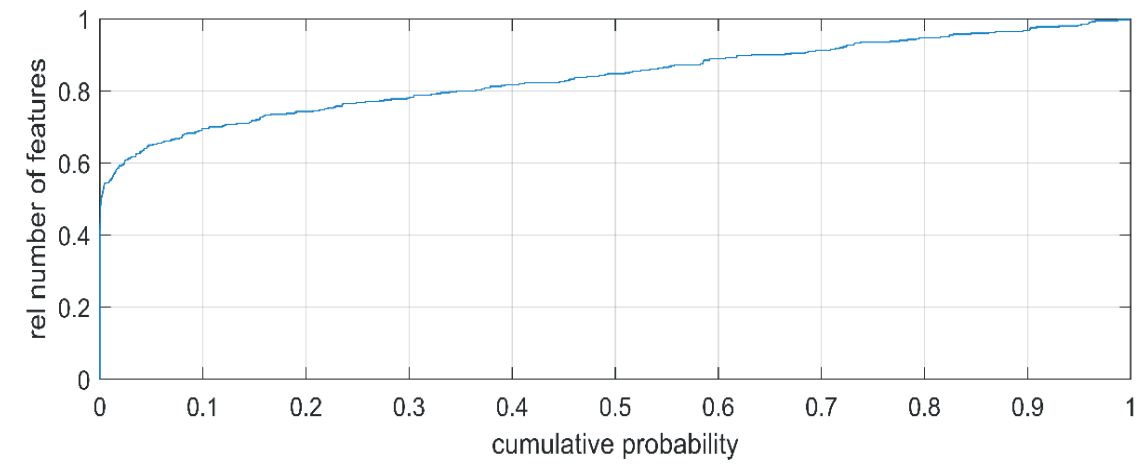

Figure 7 Empirical cumulative probability of the null hypothesis

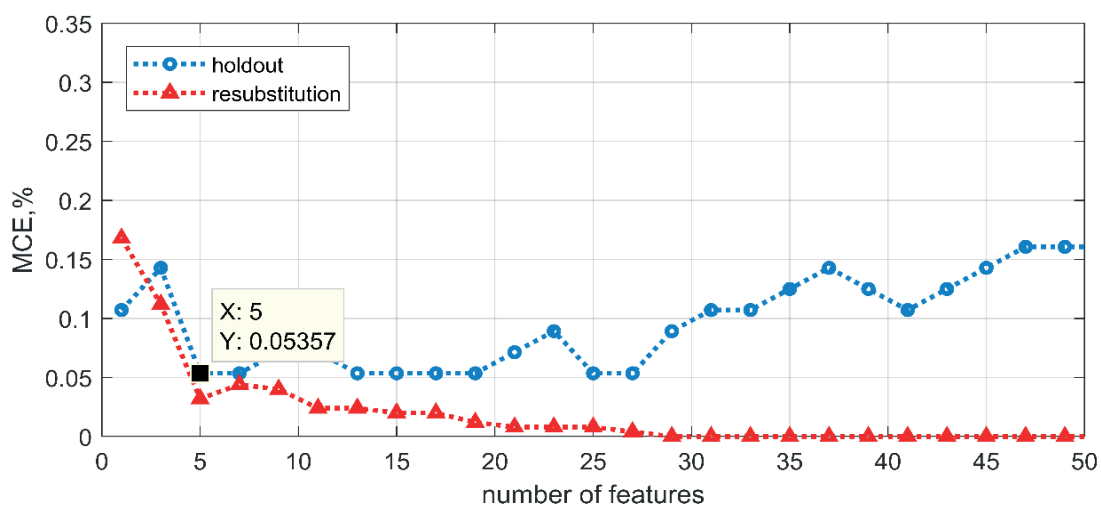

Figure 8 Results of two cross-validations with different feature sets

uncertainty is estimated with misclassification error (MCE), i.e. the number of misclassified observations divided by the number of observations.

The quadratic discriminant analysis as the classification algorithm can be used if the number of observations in each group is big enough to estimate a covariance matrix. In the presented case the number of features (400) is much larger than the number of observations (155) for the training set. The largest permissible number of features for QDA is about 70. To handle the restriction, the first 70 most probable features from t-test statistic are used for the cross validation. The t-test statistic is used as a criterion for simple filter selection method.

The successive cross-validations with different feature sets from 1 to 70 are done to find out the relation of misclassification error to the number of features. Figure 8 depicts the relation for two ways of validation: holdout (new test observations) and resubstitution (the test and training observations). The MCE for the holdout validation decreases to 0.536 for 5 features and increases if more than 27 features are used. The reason is the overfitting. The MCE for the resubstitution validation consistently decreases with the number of features and even reaches zero when more than 60 features are used. That means that the train data can not be used for estimation of the trained model.

The used simple feature selection method is simple, fast in calculations and enables reaching almost 5\% prediction error. However, the method takes into account the interaction between one pair of features and does not consider possible interaction with all other features. Some found features can be dependent on each other so that not all the features are necessary.

The more advanced feature selection algorithms can improve the performance, such as in [24-25]: sequential algorithms, exponential algorithms, randomized algorithms. Sequential feature selection is used in this research. It is one of the most widely used techniques. It selects a subset of features by sequentially forward search or removing until certain stopping conditions are satisfied. The results of sequential feature selection 


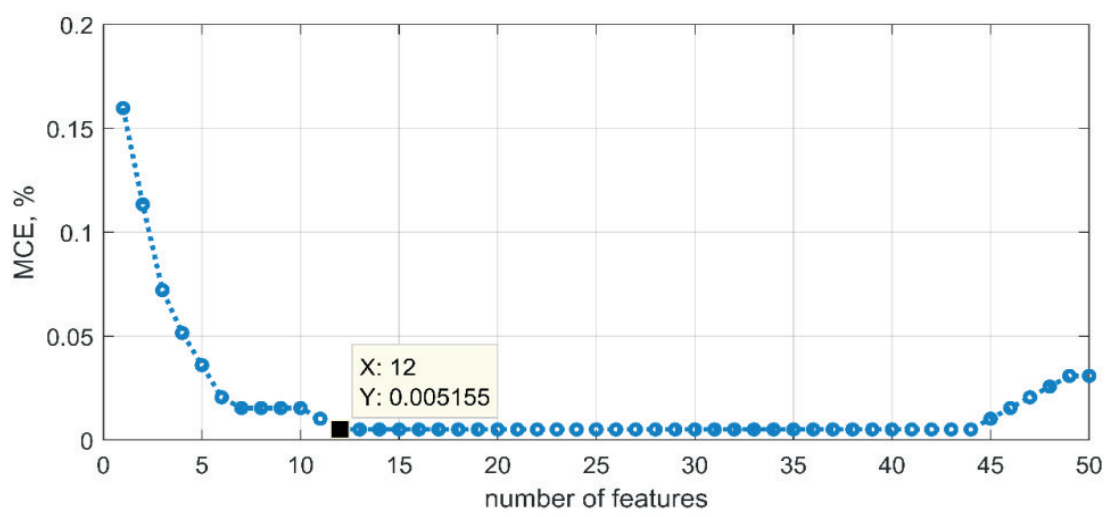

Figure 9 Results of sequential feature selection for quadratic discriminant analysis

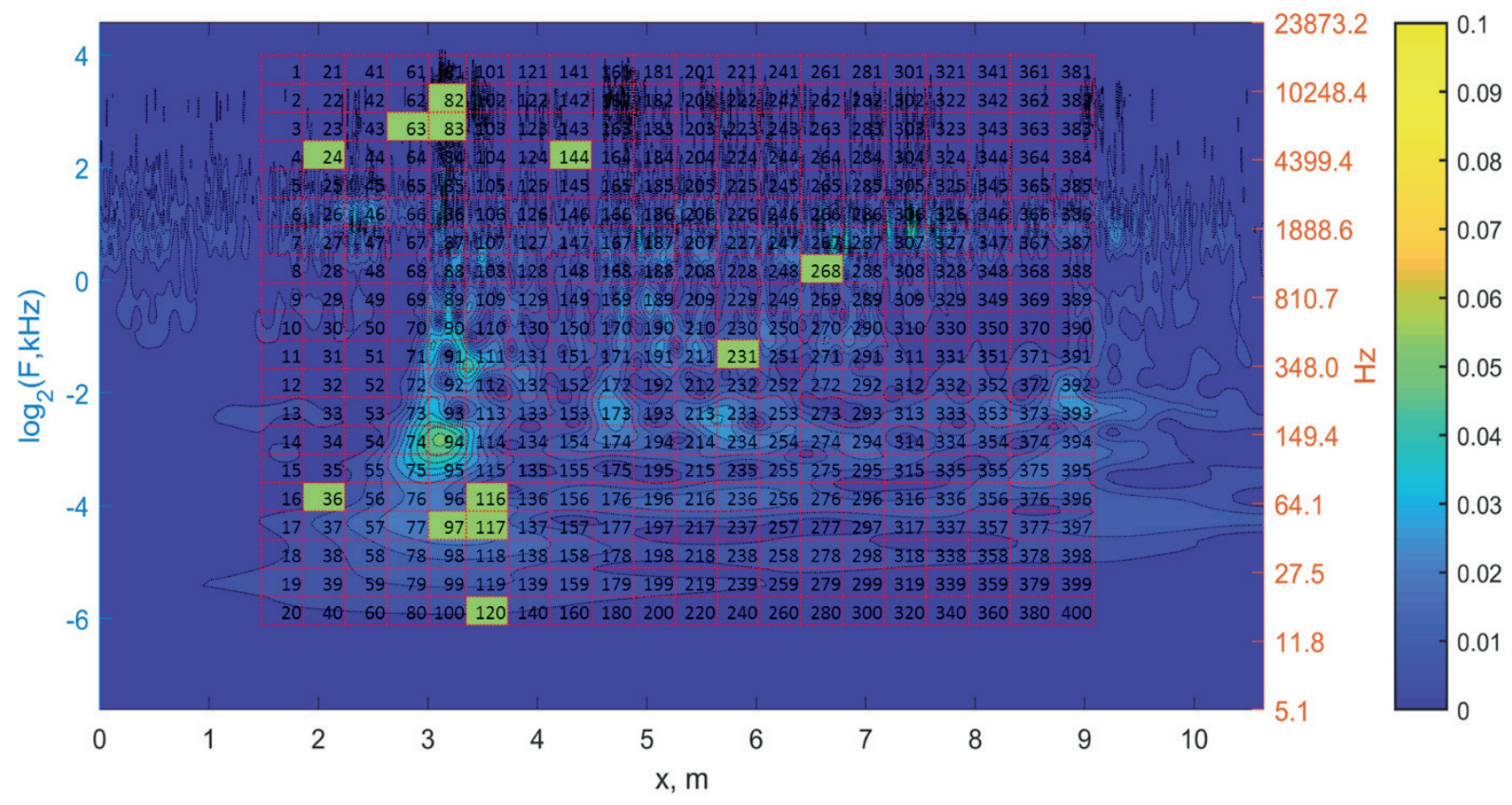

Figure 10 Features in the raster of $20 \times 20$ on the wavelet diagram with highlighted selection

for QDA are presented at Figure 9. The diagram shows that for the beginning with 12 features the minimal MCE 0.005 can be reached. The error is almost 10 times lower as for the simple filter approach due to selection of the best independent features.

The 12 selected features are depicted on the diagram of wavelet coefficients (Figure 10).

\section{Conclusion and subsequent studies}

The main aim of the actual research was to highlight the advantages of machine learning statistics vis-à-vis the simple statistical methods. The 12 found features within the sequential feature selection and quadratic discriminant analysis correspond to the most statistically significant frequencies and coordinates at wavelet diagram. The features have both low and high frequencies. Remarkably, there are almost no features corresponding to middle range frequencies where the amplitudes are the highest. The main statistical reason of the phenomena is big variance of the maximal values that makes them statistically insignificant. The secondary reason can be the close covariance of the features with already selected main features. A big variance in the middle range frequencies has also a technical reason: the different measurements are synchronised with acceleration maximal values that can cause some accidental transitions of the feature values between the neighbour features. The simple feature selection algorithm considers the transitions as error. There are different ways to cope with the problem. The simplest is the appropriate segmentations of the spectrogram. More advanced one is the feature transformation to a new feature set with feature extraction. The better measurement synchronization with waveform similarity, such as proposed in [20], is also a promising technique to solve the problem.

From the technical viewpoint, differences in low frequency range correspond to some changes in the ballast layer. At the same time, the high frequencies correspond to changes in dynamic response of the wheel-rail contact. 
Nevertheless, the present study cannot explain the principal source of changes - they may be caused by changes in rail (common crossing) as well as the ones in the wheel. The threefactor classification analysis should be carried out to separate the influence of each factor.

\section{Acknowledgement}

We would like to express the thanks to Germany Railway Company (DB Systemtechnik GmbH) and WITT ElektronikGmbH for their experimental and financial supports.

\section{References}

[1] KOVALCHUK, V., et al. Theoretical study into efficiency of the improved longitudinal profile of frogs at railroad switches. Eastern-European Journal of Enterprise Technologies [online]. 2018, 94(4), p. 27-36. ISSN 1729-3774/eISSN 1729-4061. Available from: https://doi.org/10.15587/1729-4061.2018.139502

[2] PLASEK, O., HRUZIKOVA, M. Under sleeper pads in switches \& crossings. IOP Conference Series: Materials Science and Engineering [online]. 2017, 236, 012045. Available from: https://doi.org/10.1088/1757-899X/236/1/012045

[3] GERBER, U., ZOLL, A., FENGLER, W. Verschleiß und Fahrflachenermudung an Weichenmit starrer Herzstuckspitze (Wear and rolling contact fatigue on common crossings of railway turnouts). ETR - Eisenbahntechnische Rundschau. 2015, 01, p. 36-41. ISSN 0013-2845.

[4] FENDRICH, L., FENGLER, W. Handbuch Eisenbahninfrastruktur (Field manual railway infrastructure). Berlin, Heidelberg: Springer-Verlag [online], 2013. ISBN 978-3-642-30021-9. Available from: https://doi.org/10.1007/978-3-642-30021-9

[5] ZOLL, A., GERBER, U., FENGLER, W. Das Messsystem ESAH-M (The measuringsystem ESAH-M). EI-Eisenbahningenieur Kalender. 2016, p. 49-62, ISSN 0934-5930

[6] SYSYN, M., KOVALCHUK, V., JIANG, D. Performance study of the inertial monitoring method for railway turnouts. International Journal of Rail Transportation [online]. 2018, 4(4). ISSN 2324-8378/eISSN 2324-8386. Available from: https://doi.org/10.1080/2 3248378.2018.1514282

[7] GERBER, U., ZOLL, A., FENGLER, W. Fahrzeug basierte Beurteilung des Herzstuck verschleißes (Vehicle-based assessment of wear on common crossings). EI-Eisenbahningenieur. 2013, 05, p. 26-30. ISSN 0013-2810.

[8] KOVALCHUK, V., et al. Development of a promising system for diagnosing the frogs of railroad switches using the transverse profile measurement method. Eastern European Journal of Enterprise Technologies [online]. 2018, 92(2), p. 33-42. ISSN 1729-3774/ eISSN 1729-4061. Available from: https://doi.org/10.15587/1729-4061.2018.125699

[9] MOLODOVA, M., et al. Validation of a finite element model for axle box acceleration at squats in the high frequency range [online]. Computers and Structures [online]. 2014, 141, p. 84-93. ISSN 0045-7949/ISSN-L 0045-7949. Available from: https://doi. org/10.1016/j.compstruc.2014.05.005

[10] MOLODOVA, M., LI Z., DOLLEVOET, R. Axle box acceleration: Measurement and simulation for detection of short track defects. Wear [online]. 2011, 271, p. 349-356. ISSN 0043-1648/eISSN 1873-2577. Available from: https://doi.org/10.1016/j. wear.2010.10.003

[11] MOLODOVA, M., et al. Health condition monitoring of insulated joints based on axle box acceleration measurements. Engineering Structures [online]. 2016, 123, p. 225-235. ISSN 0141-0296/eISSN 1873-7323. Available from: https://doi.org/10.1016/j. engstruct.2016.05.018

[12] SALVADOR, P., et al. Axlebox accelerations: Their acquisition and time-frequency characterisation for railway track monitoring purposes. Measurement [online]. 2016, 82, p. 301-312. ISSN 0263-2241/eISSN 1873-412X. Available from: https://doi.org/10.1016/j. measurement.2016.01.012

[13] LEDERMAN, G., et al. Track-monitoring from the dynamic response of an operational train. Mechanical Systems and Signal Processing [online]. 2017, 87, p. 1-16. ISSN 0888-3270/eISSN 1096-1216. Available from: https://doi.org/10.1016/j. ymssp.2016.06.041

[14] BOOGAARD, M., Z. LI, Z., DOLLEVOET, R. In situ measurements of the crossing vibrations of a railway turnout. Measurement [online], 2018. 125, p. 313-324. 1096-1216. Available from: https://doi.org/10.1016/j.measurement.2018.04.094

[15] LEDERMAN, G., et al. A data fusion approach for track monitoring from multiple in-service trains. Mechanical Systems and Signal Processing [online]. 2017, 95, p. 363-379. ISSN 0888-3270/eISSN 1096-1216. Available from: https://doi.org/10.1016/j. ymssp.2017.03.023

[16] GHOFRANI, F., et al. Recent applications of big data analytics in railway transportation systems: A survey. Transportation Research Part C: Emerging Technologies [online]. 2018, 90, p. 226-246. ISSN 0968-090X/eISSN 1879-2359. Available from: https://doi. org/10.1016/j.trc.2018.03.010

[17] LASISI, A., ATTOH-OKINE, N. Principal components analysis and track quality index: A machine learning approach. Transportation Research Part C [online]. 2018, 91, p. 230-248. ISSN 0968-090X/eISSN 1879-2359. Available from: https://doi. org/10.1016/j.trc.2018.04.001 
[18] BARBOUR, W., et al. Prediction of arrival times of freight traffic on US railroads using support vector regression. Transportation Research Part C [online]. 2018, 93, p. 211-227. ISSN 0968-090X/eISSN 1879-2359. Available from: https://doi.org/10.1016/j. trc.2018.05.019

[19] JAMSHIDI, A., et al. A decision support approach for condition-based maintenance of rails based on big data analysis. Transportation Research Part C [online]. 2018, 95, p. 185-206. ISSN 0968-090X/eISSN 1879-2359. Available from: https://doi. org/10.1016/j.trc.2018.07.007

[20] WANG, Y., et al. Position synchronization for track geometry inspection data via big-data fusion and incremental learning. Transportation Research Part C [online]. 2018, 93, p. 544-565. ISSN 0968-090X/eISSN 1879-2359. Available from: https://doi. org/10.1016/j.trc.2018.06.018

[21] Statistics and machine learning toolbox. The MathWorks, Inc. [online]. Available from: https://de.mathworks.com/products/ statistics/features.html

[22] RUNKLER, T. A. Data analytics: Models and algorithms for intelligent data analysis. 2. ed. Wiesbaden: Springer Fachmedien [online], 2016. ISBN 978-3-658-14075-5. Available from: https://doi.org/10.1007/978-3-658-14075-5

[23] LAROSE, D. T., LAROSE, C. D. Discovering knowledge in data: an introduction to data mining, 2. ed. John Wiley \& Sons Inc., 2014. ISBN 978-0-470-90874-7

[24] GARCIA, S., et al. Data preprocessing in data mining. Springer, Cham [online], 2014, p. 1-17. ISBN 978-3-319-10247-4. Available from: https://doi.org/10.1007/978-3-319-10247-4_1

[25] BRAMER, M. Principles of data mining. 3. ed. London: Springer-Verlag [online], 2016. ISBN 978-1-4471-7307-6. Available from: https://doi.org/10.1007/978-1-4471-7307-6 